\title{
O Ator Especial: Estudantes Especiais Atuam no Teatro de Integração
}

Juliano Borba*

Neste artigo, o projeto de Teatro Aplicado Os Astronautas, realizado com Estudantes Especiais é analisado através da narrativa em diálogo com quatro perspectivas diferentes e complementares: educação especial contemporânea; narrativa e construção de identidade; possibilidades concretas de explorar narrativa com ganhos estéticos e educacionais através do drama; e teatro como possibilidade de síntese artística coletiva da narrativa e de troca comunitária.

\section{Contexto Geral do Projeto}

O projeto Os Astronautas aconteceu no primeiro semestre de 2004 durante as aulas curriculares de arte da turma Oficina II na Escola Especial Caminho da Esperança em Palhoça, na Grande Florianópolis. Uma cidade de geografia rica em montanhas e praias e uma população proveniente, em sua grande maioria, de regiões rurais de Santa Catarina, Rio Grande do Sul e Paraná. A escola atende atualmente 128 estudantes e possui um grupo de trabalho de 33 profissionais incluindo presidente; assistente social; secretárias; motoristas; merendeiras, auxiliares de serviços gerais, fisioterapeuta e professores. Estes alunos, em sua grande maioria são provenientes dos bairros periféricos e carentes da cidade. (KATO: 2004) ${ }^{1}$.

Todos os 128 estudantes possuem algum nível de deficiência mental, 42 possuem deficiência mental e deficiência física, e destes 16 são cadeirantes; 10 estudantes possuem também deficiência visual; 6 possuem também deficiência auditiva; 18 possuem síndrome de Down e 9 possuem deficiência severa e podem ser autistas (KATO: 2004).

Como professor de arte curricular da Associação de Pais e Amigos dos Excepcionais - APAE de Palhoça, recém chegado, me deparei com professo-

* Juliano Borba é formado em Artes Cênicas pela UDESC e mestre em Teatro Aplicado pela Universidade de Exeter, Inglaterra. É professor colaborador de teatro-educação e estágio da UDESC, coordenador da ABRA - Associação Brasileira de Arteducadores e do PAPE - Projeto Aventuras do Peri. 
res e estudantes que me mostraram um folder sobre o Festival Nossa Arte da Federação Brasileira das APAEs e me pediram para realizar um montagem para os estudantes da APAE de Palhoça poderem participar deste referido evento. Com um espaço de três meses para montar a apresentação e uma carga horária apertada, foi escolhida a turma Oficina II, a mais hábil para atuar e a narrativa fantástica "Os Três Astronautas", escrita por Umberto Eco, para ser o motivo da exploração dramática para a apresentação.

Com idades diversas, variando entre 15 a 40 anos, os 12 estudantes da Oficina II em seu dia a dia escolar fazem pequenos trabalhos manuais como soldar circuitos eletrônicos, artesanato em papel e ajudam na manutenção e limpeza da escola. Eles possuem facilidade de comunicação em relação aos demais, porém não desenvolveram a capacidade de ler e escrever. A função semiótica nestes estudantes, apesar de latente, era claramente menos desenvolta do que em crianças normais. Politicamente, há um constrangimento relacionado a esta turma na escola, pois explicita o caráter segregacionista das instituições de educação especial - APAE`s, principalmente da região sul do Brasil. Em realidade estas escolas atuam desarticuladamente com as outras instituições de ensino especial e regular e não conseguem promover a integração. Os estudantes desta turma, portadores de necessidades especiais brandas, poderiam estar integrados na escola normal e possivelmente estariam lendo, escrevendo e trabalhando. Este mal estar é possivelmente aliviado na percepção mais ampla do problema educacional. A sociedade ainda se prepara para assumir criticamente as responsabilidades sociais dos sucessos e derrotas escolares como centrais para o seu desenvolvimento.

Evoluções lentas estão acontecendo. Segundo dados do senso escolar 1998-2004 sobre a política de atendimento da educação especial no Brasil, as inclusões de estudantes especiais em escolas regulares com assistência especializada subiram de $13 \%$ em 1998 para 34,4\% em 2004, sendo o menor índice, $27 \%$ em 2004, encontrado na região sul, onde o referido projeto aconteceu ${ }^{2}$. Na Declaração de Salamanca de 1994, resultado de um importante diálogo internacional sobre necessidades educativas especiais, um conjunto de diretrizes para a integração dos portadores de necessidades especiais foi proposto para as nações do mundo ${ }^{3}$. Estas apontam para a transformação das escolas e universidades em espaços integradores programados e projetados para valorizar a diversidade com uma pedagogia centrada no indivíduo e suas especificidades.

Para Dewey, um dos pioneiros a formular uma pedagogia centrada no educando, a educação deve ser baseada em problema e diversão e o professor deve se responsabilizar pelo desenvolvimento positivo de autoconceito e auto-estima propondo problemas que desafiem os estudantes den- 
tro de suas habilidades, encorajando os a vencer e reconhecendo os seus sucessos (HENSON, 2003). Estas premissas foram especialmente úteis e formaram a base da ação prática e pedagógica.

\section{O Projeto}

O envolvimento dos estudantes foi crucial para a autoridade do grupo no processo e produto artístico. Para isso adotamos um formato claro, simples e este se repetiu como um ritual, engajando-os em atividades carregadas emocionalmente e conectadas com o nível de habilidade para captar seus interesses e motivá-los. Essa estrutura serviu como ponto de apoio para o grupo, facilitando a compreensão do nosso itinerário e da estrutura para atividade artística.

No início da cada aula fizemos uma roda dialógica com cumprimentos, anúncios, coisas para contar e por fim a proposta da aula. O aquecimento era físico, psicológico/mental, emocional ou híbrido dependendo da atividade central do encontro, sendo muitas vezes realizado com músicas, bailes, cirandas e jogos. A atividade central de cada encontro foi gradualmente transitando dos jogos tradicionais e cooperativos para os jogos teatrais, exploração prática da narrativa e depois a composição e repetição/ensaio das cenas do espetáculo. No fim de cada encontro, fizemos uma roda de avaliação com o objetivo de recapitular o encontro e selecionar os melhores momentos.

Esta avaliação final foi explorada através de diversas linguagens, principalmente verbal, imagem corporal, dança e desenho.

No início do ano letivo, antes do projeto de montagem ser iniciado, propusemos uma estrutura de jogos tradicionais, colaborativos e teatrais com intuito de tornar as aulas de arte um ambiente motivador e prazeroso, bem como para coletar as primeiras informações sobre o potencial dos estudantes de uma forma sutil e lúdica. Na primeira aula, por exemplo, usando a estratégia do professor-personagem, entrei na sala como um repórter e entrevistei os alunos. Com um pincel atômico de microfone, obtive dos que podiam se comunicar oralmente informações como nome, principais atividades, onde moram, atividades prediletas, etc. Com os dados coletados do grupo improvisei com violão uma música usando essas informações, salientando muito bem o nome de cada um e suas qualidades. O violão foi então compartilhado para quem quisesse cantar a sua música.

Na segunda aula, acompanhando o interesse do grupo por música, propus uma ciranda. Dançamos uma ciranda de passo simples e alguns sentiram dificuldade em acompanhar, principalmente uma estudante que possuía 
dificuldade de locomoção e de permanecer em pé. Mesmo assim ela quis participar e o fez com o apoio generoso do grupo. Na seqüência construímos uma coreografia de composta por movimentos e sons através da união da contribuição individual. Ou seja, cada participante propunha um movimento e som e essa proposta ia se unindo às dos outros participantes. Esta coreografia criada coletivamente foi proposta e repetida como aquecimento para os jogos colaborativos e teatrais no encontro seguinte. Era uma forma de utilizarmos e entendermos na prática o conceito de Zona de Desenvolvimento Proximal de Vygotsky (1998) ${ }^{4}$. Pudemos perceber o nível extremamente gradual de autonomia do grupo na realização da atividade. Sempre buscamos repetir algo significante do encontro anterior, atividades, jogos, coreografias e por fim as cenas. Essas últimas foram repetidas exaustivamente sempre contando com a típica motivação e generosidade do grupo.

Para estes estudantes com necessidades educativas especiais moderadas, com habilidades de relacionamento, noção de identidade e narrativa limitadas, porém com disposição e generosidade muito acima da média, a estrutura dos jogos teatrais de Viola Spolin, apesar de complexa, se tornou um método particularmente interessante para treinamento do ator especial quando explorada de forma simplificada em seus três elementos chave foco, instrução e avaliação - de forma gradual, repetida e com a participação dinâmica do facilitador dentro e fora do jogo.

A roda no fim do encontro para avaliar nosso itinerário possibilitou perceber a função narrativa como um desafio comum à maioria dos participantes da montagem. Eles não tinham facilidade de organizar a experiência vivida e narrá-la ao grupo. Possuíam conseqüentemente dificuldade de assimilar e acomodar histórias com uma trama complexa. Esse foi meu primeiro grande desafio da montagem. Introduzir a história escolhida, Os Astronautas, para poder improvisar e montar o espetáculo.

Ao mesmo tempo, aconteciam virtuoses narrativas que nos impressionavam. Um exemplo disso aconteceu em um encontro na fase intermediaria do projeto. No aquecimento a proposta era para cada participante cantar e dançar uma música calma tocada por mim no violão, enquanto o restante do grupo imitava. Quando foi a vez de Jedson, ele sem esforço dançou a vida dele, resumindo naquela dança sua relação com a família, a religião, os amigos, a escola, através de um jogo gestual maravilhoso. Marina, estagiária de jornalismo que estava documentando se emocionou muito com a beleza e a sensibilidade que ficou em prantos de choro. Revelou estar apaixonada pelos participantes e seus processos. Ela tornou-se uma colaboradora assídua. 
A escolha da história se justificou por ter uma trama simples, por seu poder lúdico e questionador. Narrei a história para o grupo seguidamente ao mesmo tempo em que objetivamos a preparação teatral destes participantes, ou seja, facilitamos de forma prática seu entendimento de cena, de espaço cênico, de ação, personagens sem introduzir, no entanto conceitos. Para o grupo entender e explorar a narrativa, depois desta haver sido contada repetidas vezes, dividi a história em seis partes (1- Preparação para a grande viagem; 2- A Nave Espacial; 3- Explorando Marte; 4- Saudade da Terra; 5- Amizade com os Inimigos; 6- O Marciano: beleza na diferença.) e passamos a entender cada parte isoladamente. No início usamos imagens congeladas coletivas adaptando Teatro-Imagem de Boal. Depois propomos improvisações dirigidas usando a estrutura de jogos teatrais que estava já sendo praticada e finalmente decidimos por continuar e finalizar o processo através da composição das cenas.

De fato as improvisações da narrativa não funcionaram tão bem como as experiências com os jogos teatrais no início dos trabalhos. Os atores ficavam perdidos, sem saber o que fazer, sem pontos de referência em relação ao que a narrativa propunha, mesmo depois de avaliarmos e repetirmos as atividades. Com exceção das improvisações sem fala, que não apenas funcionaram, mas possibilitaram perceber que havia um desafio intransponível para o grupo dentro do tempo que dispúnhamos: unir ao gestual corporal a voz e o verbo para comunicar a narrativa.

Tornou-se, a partir dessa avaliação, uma opção de encenação, montar o espetáculo privilegiando o corpo e a música e sem falas. Experimentamos também entrevistar os personagens, congelar a cena e pedir para os atores falarem o que seu personagem estava pensando naquele momento, porém estas propostas estavam além das possibilidades gerais do grupo para aquele momento. Passei então a usar os materiais propostos até então para compor e dirigir as cenas diretamente.

A fase de produção do espetáculo foi intensa e contou com o apoio e flexibilidade de toda a equipe do APAE de Palhoça e especialmente com o apoio da professora Arlita Benz com a produção dos figurinos e adereços. Conseguimos com a Universidade Federal de Santa Catarina uma visita ao Planetário com o intuito apresentar ao grupo novas questões e possibilidades relacionadas aos planetas, viagens espaciais, estrelas, vida fora da terra, entre outros. A saída dos alunos da escola, a interação com os profissionais da Universidade e o que eles puderam vivenciar dentro do Planetário foram extremamente importantes, pois geraram novos parâmetros, informações e motivação. Entendi essa saída não apenas como parte de um processo para composição do espetáculo, mas um evento, uma integração social, um resul- 
tado em si.

Três meses depois do início do projeto, estreamos com o espetáculo em construção, na própria escola, com uma platéia de alunos e professores. Um debate informal com os professores, depois da apresentação, nos possibilitou ajustar detalhes para a segunda apresentação, no Festival Nossa Arte, para uma platéia de alunos especiais e professores em sua maioria. A crítica foi positiva, recebemos o prêmio principal da categoria artes cênicas, pois se tratava de um festival competitivo. Os estudantes queriam apresentar mais, estavam encantados com a receptividade das platéias: os aplausos, os abraços e tapas nas costas de parabéns os impressionaram positivamente. Adaptamos o espetáculo para a rua e participamos de um evento comunitário sobre o Meio Ambiente. Apresentamos para uma platéia de crianças das escolas públicas e particulares da cidade de Palhoça. Fomos convidados a apresentar na XI Semana da Sociedade Inclusiva no SENAC para uma platéia de profissionais e interessados em Necessidades Especiais.

Recebemos outros diversos convites para apresentação, em escolas normais, em eventos e festas, porém a rotina de apresentação obriga toda a escola a trabalhar mais, os motoristas precisam transportar o grupo, cenário e figurino, os professores precisam se adaptar as saídas, a direção precisa organizar as coisas, acarretando trabalho extra para quem já trabalha demais, ganha pouco e carece de motivação. Os convites apresentados à direção para as apresentações na comunidade e eventos foram um a um recusados e o projeto foi morrendo aos poucos, mesmo com a insistência dos estudantes que persistiram interessados durante todo o segundo semestre.

\section{Jogos, Narrativa e Repetição na Formação do Ator Especial}

A formação desse grupo de atores especiais aconteceu dentro de três perspectivas metodológicas: jogos, exploração da narrativa e repetição. De acordo com Peter (2003) brincadeira, jogo, drama e teatro possibilitam o fortalecimento de partes do funcionamento do cérebro necessárias para um pensamento mais flexível, habilidades de comunicação, e maior sensibilidade para as interações sociais. Teatro e drama, por sua vez, oferecem uma estruturada oportunidade de participação do mundo social. Como uma arte social, teatro possibilitou a esses atores especiais contato com conflito e narrativa e conteúdos transversais como Identidade, Cultura, Viagem, Diferenças Humanas através da interdisciplinaridade do drama de forma gradual, ao mesmo tempo experimentavam possibilidades de comunicação através do corpo-voz, não necessariamente dimensionadas pela linguagem verbal.

O processo de exploração artística foi informado pelas premissas educa- 
cionais do Construtivismo de Piaget e do Sócio-Interacionismo de Vygotsky, exemplos de pedagogias centrada no estudante. Esse entendimento de possibilitar a construção do conhecimento através da ação reflexiva - que se abria para avaliação do grupo possibilitando um melhor entendimento da experiência vivida - e possibilitar uma interação humana colaborativa - valorizando as diferenças humanas presentes - se tornou evidentemente necessária no trabalho de teatro-educação com a turma Oficina II. Para usar essa perspectiva educacional de forma concomitante e interligada, foi preciso entender como cada individuo poderia ali realizar a função de ator criativo no processo de construção do espetáculo. Foi clara a necessidade de conhecer cada indivíduo daquele grupo em sua humanidade, através de detalhes sociais, econômicos, e dimensões subjetivas e imaginárias. Essas informações foram obtidas e alimentaram as trocas sociais que aconteceram no início do trabalho com o grupo e foram importantes para mapear as reações, expor contradições, e segundo Mantoan (1989:135) quando acontecem de forma intensa e emocional, criando conflitos que obrigam o sujeito a reagir, possibilitam a diminuição gradativa das deformações cognitivas.

Para esse mapeamento idealizamos um questionário de avaliação para ser usado como referencial para identificar os desenvolvimentos individuais. Adaptamos posteriormente a uma estrutura similar, porém mais complexa, usada por Gaynor Peach (2003:15), que por sua vez emprestou de Flo Longhorn (2000:6).

"Vontade de responder a situações de aprendizado; desenvolvimento da atenção e foco; consciência de si, dos outros e do meio; 1nteração com os outros; iniciativas lúdicas, participação em jogos; iniciativas de comunicação de qualquer modo; iniciativas de diversão; coordenação e desenvolvimento sensório-motor; respostas a recompensas e sanções; habilidades de remover barreiras ao aprendizado; interação com o ambiente" (PEACH 2003: 15).

Dentro desse contexto, para analisar coletivamente os significados de cada experiência vivida e para avaliar o desenvolvimento individual dos atores/estudantes especiais, utilizamos representações através de desenhos, imitações, jogos, brincadeiras de faz de conta, expressão gestual, teatro imagem, teatro-fórum, entrevistas e estímulos.

Atividades lúdicas em artes e drama podem ligar a lacuna entre o comportamento brincalhão das crianças e a aparente falta dessa característica encontrada em muitas crianças com necessidades complexas e severas. Contudo essa fronteira será mais facilmente cruzada através da segurança 
de uma estrutura clara que se repete para as situações de jogo propostas, libertando-os para decisões e escolhas dentro de fronteiras gradualmente crescentes. Como exemplo dessa necessidade de estrutura clara e repetente, Gaynor Peach (2003), no projeto de pesquisa com oito crianças portadoras de necessidades educativas severas e complexas na Inglaterra, cantou a mesma música de bom dia com a ajuda de um boneco de mão para o grupo durante o ano inteiro, isso significou 1400 vezes a mesma música. Como resultado ela celebrou a participação tímida e gradual dessas crianças que conseguiam antever o que viria na brincadeira.

Estudos psicológicos sobre o desenvolvimento humano, baseados principalmente nas contribuições de Piaget, centraram-se em como o ser humano faz sentido das experiências e internaliza sua percepção através de representações mentais, e que estas, por sua vez, influenciam seu comportamento e entendimento. A forma significativa para esse processo é a da narrativa, explorada através dos jogos dramáticos, simbólicos e do faz de conta. Um exemplo desse processo narrativo, o comportamento tipicamente brincalhão das crianças, consiste em sua forma de pesquisa e conexão com o mundo e pode revelar seus entendimentos e sentimentos para com fatos, eventos e pessoas (PETER, 2003:21).

Esta rota para a competência social, porém, é menos direta e possível para crianças e indivíduos com necessidades educativas especiais, que carecem de habilidades espontâneas para entender as experiências e/ou interagir com as pessoas e com o ambiente. Segundo Piaget (1971), as experiências sensório-motoras são consideradas a fundação das habilidades para formar representações e entendimentos conceituais. Para Vigotsky (1998), a forma com que os adultos mediam a interação entre as crianças e interagem com elas nestas oportunidades de jogo, afetará a maneira como elas subseqüentemente aprenderão sobre o ambiente e o modo de se compreenderem como parte da sua cultura e da sua sociedade. Esta premissa é especialmente verdade para as crianças e indivíduos que dependem dos adultos para ter acesso aos jogos, socializações e outras oportunidades do ambiente.

\section{Narrativa: construção de identidade e exploração dramática}

Foi na transformação da narrativa através do drama e depois para o teatro ocorreu muito do trabalho artístico e criativo em Os Astronautas. Para isso acontecer foi preciso entender como trabalhar o drama para explorar a narrativa, que possui em si uma estrutura e uma simbologia dentro do nível médio de possibilidade do grupo $O$ entendimento de narrativa para além da arte foi fundamental. Narrativa está em quase tudo o que existe. Muitas de 
nossas experiências no mundo são através de narrativa, quando narramos, ou por outra, socializamos nossas experiências, e como receptores, quando experiências de outros são divididas conosco. Além de arte, narrativa, enquanto primeira ação mental, é essencial para a construção da nossa identidade pessoal e coletiva. "Narrativa não é uma invenção estética criada por artistas com o objetivo de controlar, manipular ou ordenar experiências, mas um primeiro ato da mente transferido da vida para a arte" (HARDY, 1987:1 in COCKETT, 1999:65).

É importante entender o subtexto das histórias criticamente. As narrativas são também base para sustento e a conquista do poder. A maioria das histórias a que somos expostos, como as histórias usadas pelos estúdios Disney, por exemplo, não desafia o status quo ou da esperança e força para as pessoas levantarem suas vozes e agirem no sentido de uma transformação ${ }^{5}$. Narrativa toca o centro dos sistemas culturais, políticos e sociais e é usada como ferramenta para sustentar ou resistir relações de poder.

Se for preciso ter boas histórias para o teatro, é certa a necessidade de escolher boas histórias para o trabalho educacional através do drama. Uma história naturalista, que depende de um realismo psicológico tem menos utilidade do que aquelas que permitem tratamento estilizado.

\begin{abstract}
"Boas histórias exploram alguma coisa significativa da condição humana.

Elas agitam nossa imaginação, nos conectam com o mundo em um sentido que não é puramente pessoal. Boas histórias fazem seus ouvintes compreenderem seus significados por si próprios" (COCKETT, 1999:71).
\end{abstract}

A decisão do que é uma boa história pode ser encontrada através de uma série de perguntas: "A história pode ser contada através da ação? Que tipo de transformação acontece na história? Em que sentido a história fica diferente no final em relação ao começo? Existe um momento em direção ao qual a história converge? Você pode dizer exatamente onde e quando? Quais os valores e princípios presentes na história? Sobre o que a história é realmente?" (Ibid). E dentro dessa história escolhida o professor deve possibilitar aos alunos entenderem o ápice da história, o seu momento mais importante, onde ocorre a transformação. Cocket propõe que a história seja dividida em unidades e cada unidade uma ação-chave/ imagem-chave. Em cada unidade as perguntas centrais são: como isto pode servir para a narrativa? Onde você quer que a platéia coloque seu foco? Como isto vai estimular a imaginação do público? Esta proposta pode ser determinada pela ação e esta pode estar ligada ao significado implícito da história (Ibid). Já Cecily 
O’Neill, indo por outra via, acredita que a história pode servir com pré-texto e este precisa ser transformado e recriado através do drama. O professor deve ser hábil em explorar a história, modificá-la, usar os personagens não mencionados, entrar nas perspectivas pessoais e globais das ações dos personagens, avançar ou retroceder no tempo.

"Experiências dramáticas significantes não surgirão necessariamente da simples adaptação e dramatização do que parece ser um pré-texto apropriado. Este enfoque parece ir mais em direção a um trabalho explanatório do que exploratório, em que as idéias e temas são demonstrados ao invés de serem descobertos e explorados" (TAYLOR, 1995:17).

Estas duas posições acima apresentadas por Cockett e O'Neill, foram as referências principais para os trabalhos de exploração dramática e complementaram a fundamentação teórica baseada em Freire (1977) e Boal (1998). Inicialmente usando a estrutura que a narrativa escolhida propõe e gradualmente introduzindo formas de explorar e recriar os momentos escolhidos dentro das possibilidades do grupo.

\section{A História}

A narrativa escolhida, Os Três Astronautas de Umberto Eco, conta sobre uma corrida internacional para chegar ao planeta Marte. Três países poderosos e inimigos escolheram seus astronautas mais especiais para completar essa missão. Partiram então o astronauta Russo, o Americano e o Chinês. Mesmo tentando chegar primeiro, ironicamente todos chegaram ao mesmo tempo em Marte. Eles então, individualmente examinam o planeta durante todo o dia. As montanhas eram vermelhas, as arvores andavam e eram amarelas, os rios corriam paralelos ao chão e eram verdes. Tudo era bem diferente do planeta Terra. A noite chegou e fez um silêncio enorme. Os astronautas ficaram com saudade da terra. Eles se olharam e tentaram esboçar um sorriso. Apesar de línguas diferentes eles perceberam que possuíam sentimentos semelhantes, saudade, frio, fome. Sentaram juntos e aprenderam a se conhecer.

Quando amanheceu eles perceberam um barulho muito estranho. Um ser verde muito feio e estranho, com um nariz em forma de tromba, antenas no lugar de orelhas e seis braços saiu do meio de algumas árvores. Era horrível vê-lo! Ele disse: GRRRR. Na língua dos marcianos isso significava: Quem são esses seres horríveis!? Os terráqueos acharam que significava algum grito de guerra e decidiram matá-lo com suas armas atômicas. Neste momento um pássaro marciano caiu do seu ninho e começou a piar sem 
parar, de medo e frio, como se estivesse chorando. Então o marciano soltou fumaça de seu nariz, segurou a pássaro entre os braços para aquecê-lo. Os terráqueos perceberam que o marciano estava chorando à sua maneira. Eles entenderam que o marciano gostava dos animais e tinha sentimentos. Baixaram as armas e se aproximaram do marciano estendendo a mão. Este que possuía seis braços conseguiu cumprimentar a todos e ficaram amigos. Quando os terráqueos partiram o marciano prometeu retribuir a visita.

\section{Reflexões Finais}

O processo de treinamento do ator especial - explorar e entender narrativas, personagens em situações diversas, explorar possibilidades lúdicas e comunicativas do corpo e da voz possibilitou desenvolvimento humano, cognitivo e social. Para estudo dividimos o planejamento, execução e avaliação em três áreas: jogos - para desenvolver a capacidade de usar o corpo espontaneamente. Foi trabalhando de forma extremamente gradual, sendo que muitos deles foram desafiantes de mais para a capacidade atual do grupo; exploração dramática da narrativa - que foi o trabalho sobre a história e a temática e como transformá-la em imagem e ação; e a repetição - a perspectiva de repetir o máximo de coisas que funcionaram para um contato maior e mais tranqüilo com a experiência.

Para isso foi necessário contextualizar a prática, saber mais quem são esses atores ao mesmo tempo em que realizamos aspectos teóricos do desenvolvimento humano e do que poderia ser a educação transformadora e crítica desse ator especial. Por exemplo, o entendimento prático do que Vygotsky chama de ZDP - Zona de Desenvolvimento Proximal foi importante para avançarmos gradualmente no processo de formação deste ator. Avançamos gradualmente percebendo que atividades podiam realizar com auxílio do facilitador. Trabalhamos através da repetição para eles conquistarem habilidade de resolver o problema com o auxílio próprio grupo. Cada nova habilidade e independência nos informavam que poderíamos passar para algo mais desafiante, consolidando o aprendizado e criando zonas de desenvolvimento proximais sucessivas.

A visão contemporânea da educação entende o ser humano integrado na natureza e sociedade valorizando a diferença, a democracia e a transformação como parte fundamental da vida humana na terra. Dentro dessa premissa, a instituição de educação especial deveria atender diretamente apenas os indivíduos que ainda não estão preparados para serem integrados. O novo paradigma dessas instituições se direciona a constituírem-se como centros formadores de profissionais integradores dos estudantes especiais. 
Indo neste caminho, o Ministério da Educação - MEC lançou um projeto nacional de educação especial chamado Educação Incluída: Direito a Diversidade. O projeto está em uma fase piloto acontecendo em 109 municípios do Brasil, com o objetivo de capacitar educadores e transformar os sistemas de ensino isolados e desarticulados em sistemas integrados e inclusivos. Contudo, as políticas de educação especial estão se desenvolvendo ainda desconexas às vanguardas educacionais propostas em Salamanca em 1994. Estas políticas e ações precisam transformar as escolas em espaços inclusivos, democráticos e críticos capazes de fomentar a mobilização, a construção do saber e um ambiente de luta por um mundo melhor possibilitando a transformação dos diversos setores da sociedade.

No caso do projeto Os Astronautas foi claro perceber a resistência geral, porém sutil da escola pouco depois do seu início. Não somente porque suas ações promoviam questionamentos e propostas de novos paradigmas, mas porque esta ação cultural e pedagógica movimentava a rotina da escola, de alimentação, transporte, horários de outros professores. Estas propostas obrigam novas posições, flexibilidade de organização, conhecimento e mudança. As contradições da educação não param ai. O projeto Os Astronautas foi motivado por um festival competitivo com a função de eleger as melhores obras.

As ações e iniciativas precisam ser radicais em promover os valores e princípios humanos resistentes às ideologias dominantes sutilmente trabaIhadas em nosso habitus ${ }^{6}$ com o poder de nos fazer agir de forma competitiva e elitista em nome de uma educação popular inclusiva e transformadora.

\section{Notas}

${ }^{1}$ Deficiência mental é um funcionamento intelectual geral significativamente abaixo da média, oriunda do período de desenvolvimento, concomitantemente associadas a duas ou mais áreas da conduta adaptativa ou da capacidade do individuo em responder as demandas da sociedade, nos seguintes aspectos: comunicação; cuidados pessoais; habilidades sociais; desempenho na família e sociedade; independência na locomoção; saúde e segurança; desempenho escolar; lazer e trabalho. (BRASIL, 1998)

2 Dados atualizados através do portal eletrônico do Ministério da Educação http://portal.mec.gov.br/seesp/index.php?option=content\&task=view\&id=110

${ }^{3}$ Conferência Mundial de Educação Especial com delegados representantes de 88 países e 25 organizações internacionais se reuniram em Salamanca 
na Espanha de 7 a 10 de junho de 1994 e resultou em uma declaração que focaliza os governos e organizações a reconhecerem a necessidade urgente de possibilitar que crianças, jovens e adultos portadores de necessidades especiais possam freqüentar as instituições regulares de ensino transformadas em instituições modernas e inclusivas.

${ }^{4}$ ZDP - Zona de Desenvolvimento Proximal é um dos conceitos mais importantes de Vygotsky. Para ele o indivíduo possui, além do desenvolvimento real, ou seja, aquilo que ele pode realizar sozinho, um estágio de desenvolvimento intermediário, chamado de proximal ou potencial, correspondente ao que o indivíduo pode realizar com a ajuda do facilitador ou do grupo. Para mais ver Vygostky 1998.

${ }^{5}$ Ver Zipes 1997 para mais informação sobre Disney e industria cultural.

${ }^{6}$ Habitus é conceituado por Bourdieu (1979) como um conjunto de ações ideológicas inconscientes, determinações sociais, sistema de disposição e de percepção, "estruturas estruturadas predispostas a funcionar como estruturas estruturantes", com poder para programar a produção, circulação e o consumo dos indivíduos e classes. Um conceito com potencialidade para possibilitar a observação e identificação das forças ideológicas hegemônicas ligadas aos interesses sutis dominantes. Para uma interessante análise prática deste conceito ligada ao contexto latino americano ver Canclini 1995:62;79-80.

\section{Bibliografia}

BETTELHEIM, B. The Uses of Enchantment. London: Thames and Hudson, 1976.

BORBA, J. Community Theatre: local stories in international perspectives. Dissertação Não Publicada (Master in Applied Drama). University of Exeter , 2002.

BOURDIEU, P. La reproducción, Barcelona, Laia, 1977.

BOURDIEU, P. La distinción, Paris, Minuit, 1979.

CANCLINI, N.G. Ideologia, Cultura y Poder, Buenos Aires, Oficina de Publicaciones-UBA, 1995.

CONFERÊNCIA MUNDIAL SOBRE NECESSIDADES EDUCATIVAS ESPECIAIS: ACESSO E QUALIDADE. Declaração de Salamanca e linha de ação sobre necessidades educativas especiais. Brasília, CORDE, 1994.

COCKETT, S. Das Histórias ao Teatro. IN: CABRAL, B. (org) Ensino do Teatro: Experiências Multiculturais. Florianópolis: Imprensa 
Universitária, 1999.

DEMO, P. Educar pela pesquisa. 3 ed. Campinas: Autores Associados, 1998.

ECO, U. Os Três Astronautas. Ilustrações de Eugênio Carmi, São Paulo: Àtica, 1999.

FREIRE, P. Pedagogia do Oprimido. R.J. Paz e Terra, 1977.

SOARES, A. Avaliação do processo de integração de alunos com necessidades especiais na rede estadual de ensino de Santa Catarina no período de 1988 a 1997. São José: Fundação Catarinense de Educação Especial, Gerên, 2002.

GERGEN,K.J. \& GERGEN, M.M. Narratives of Self, IN: HINCHMAN, L.P. \& HINCHMAN, S.K. (Ed.) Memory. Identity, and Community. Albany: SUNNY, 1997.

GROVE, N. Literature for All. London: David Fulton Publishers, 1998.

GROVE, N. \& PARK, K. Social Cognition through Drama and Literature for People with Learning Disabilities. London: Jessica Kingsley, 2001.

HANSEN, L.L., et. al., Special education students' perceptions of their mainstreamed classes. IN: Education (Chula Vista, Calif.) v. 118 no. 4, 1998, p. 610-5.

HARDY,B. Tellers and Listeners: The Narrative Imagination. London: Athlone Press, University of London, 1975.

HENSON, K.T. Foundations for Learner Centered Education: A Knowledge based education. IN: Education (Chula Vista, Calif.) V124 no. 1, 2003, pp 76 a 85.

JONES, P. Drama as Therapy, Theatre as Living. London: Routledge, 1996.

MACLEAN, J. An Aesthetic Framework in Drama: Issues and Implications. Brisbane: NADIE, 1996.

MANTOAN, M. T. E. Compreendendo a deficiência mental: novos caminhos educacionais. São Paulo: Scipione, 1989.

MARTINS, Marcos B. O Professor como mestre-encenador: Os fundamentos do laboratório de encenação da UFRN. IN SANTANA, Arão P. (Coord.). Visões da Ilha: apontamentos sobre teatro e educação. São Luiz, Ed. Grupo de Pesquisa Ensino do Teatro, 2003.

NOVITZ, D. Art, Narrative, and Human Nature, IN: HINCHMAN, L.P. \& HINCHMAN, S.K. (Ed.) Memory. Identity, and Community. Albany: SUNNY, 1997.

KATO, C.E.W. APAE de Palhoça. Palhoça (SC). Relatório não publicado, 2004.

KEMPE. A. Drama Education and Special Needs. Cheltenham: 
Stanley Thornes. 1996.

O'NEILL, C. Drama worlds: a framework for process drama. Portsmouth: Heinemann, 1995.

PETER, M. Drama for All. London: David Fulton Publishers, 1994.

PETER, M. Making Drama Special. London: David Fulton Publishers, 1995.

PETER, M. Drama, narrative and early learning, IN: British Journal of Special Education. v. 30, no.1, 2003, p.21-6.

PIAGET, J. A Formação do Símbolo na Criança: imitação, jogo e sonho, imagem e representação. Rio de Janeiro: Zahar,1971.

PIAGET, J. A Linguagem e o Pensamento da Criança. São Paulo: Martins Fontes, 1993.

ROSEN, H. Stories and Meaning. Sheffield: NATE, 1975.

SHERRATT, D. \& PETER, M. Developing Play and Drama in Children with Autistic Spectrum Disorders. London: David Fulton Publishers, 2002.

SLADE, P. \& LAFITTE, E. \& STANLEY, R.J. Drama with Subnormal Adults. London: Educational Drama Association, 1975.

SOMERS, J. Drama e História: Projeto Peste Negra, IN: CABRAL, $B$. (org) Ensino do Teatro: Experiências Multiculturais. Florianópolis: Imprensa Universitária, 1999.

SPOLIN,V.Improvisações para o Teatro. Trad.: Ingrid Domien Koudela e Eduardo José de Almeida Amos, São Paulo, Perspectiva, $4^{\text {a. }}$. Ed. 2003.

SUTTON-SMITH, B. (Ed.) Play and Learning. New York: Gardner, 1979.

TAYLOR, P. Pre-Text and Storydrama: The Artistry of Cecily O'Neill and David Booth. Brisbane: NADIE, 1995.

TRAGTENBERG, M. Sobre Educação, Política e Sindicalismo. SãoPaulo: Editores Associados; Cortez, 1990, $2^{\mathrm{a}}$ ed.

VIGOTSKY, L.S. A Formação Social da Mente: o desenvolvimento de processos psicológicos superiores. São Paulo: Martins Fontes,1998.

WING, L. The Autistic Spectrum: a guide for parents and professionals. London: Constable, 1996.

ZIPES, J. Happily Ever After: Fairy Tales, Children and the Culture Industry. London: Routledge, 1997. 